\title{
TOWARDS SCREENING THE ENHANCE OF LUMINESCENCE PROPERTIES OF OXIDIZED TANNINS BY A FENTON-LIKE REACTION
}

\author{
Alexandru Gonta \\ Institute of Chemistry of Academy of Sciences of Moldova, 3, Academiei str., Chisinau MD-2028, Republic of Moldova \\ e-mail: alexandru.gonta@chem.asm.md
}

\begin{abstract}
After modification of enotannins, flavonols monomer units could be obtained with polyfunctional properties. Moreover, polyphenols are known to generate $\mathrm{H}_{2} \mathrm{O}_{2}$ and other free radicals under alkaline conditions. Reactive oxygen species generation and catalytic influence of ferrous ions enhance the chemiluminescence light. Therefore, Oxidized Tannin/Tris-EDTA/ $\mathrm{Fe}^{2+}$ ions system have been used for screening luminescent properties of oxidized tannins.
\end{abstract}

Keywords: oxidation, tannins, free radical, chemiluminescence.

Received: April 2015/Revised final: May 2015/ Accepted: May 2015

\section{Introduction}

One of the most abundant classes of natural compounds found in plants, with advanced therapeutic properties and polyfunctional morphological structure, is considered flavanoid group. These polyphenols contain compounds with monomeric unit, such as quercetin, catechin, rutin, luteolin, kaempherol, or oligo-polymeric chain, such as condensed and hydrolyzable tannins. Significant sources of tannin content with remarkable antibacterial properties, can be found in grape seeds from local Moldavian wine industries [1,2]. Moreover polyphenols are known for their potent antioxidant activity, that have been widely discussed in the literature as efficient free radical scavengers [3]. Polyphenols are exhibiting their antioxidant potential through a complex red-ox mechanism, which mainly is considered to be triggered after hydrogen abstraction followed by electron-donor transfer to molecules with unpaired electrons in their ground state. These unpaired electrons define molecules as highly chemically active, that could act as oxidant species $[4,5]$.

ROS species

Among dangerous oxidant species are considered reactive oxygen species (ROS) such as superoxide anion radical $\left(\mathbf{O}_{2}^{--}\right)$, singlet oxygen $\left(\mathbf{O}_{2}\left(\mathbf{a}^{1} \mathbf{\Delta}_{\mathbf{g}}\right)\right)$, hydroxyl radical $(\mathbf{O H})$ and hydrogen peroxide $\left(\mathbf{H}_{2} \mathbf{O}_{2}\right)$, which are known for their destructive mediated action of lipids, proteins and cell DNA. Singlet oxygen is the most active ROS with a lifetime of 40 minutes in ultrapure water, but with a short decay of action within microseconds after excitation in the presence of other transition metals and other radicals [6,7].

Reactive oxygen species are formed by electron's addition to $\mathrm{O}_{2}$, which proceeds through a complex mechanism with evolution of superoxide anion radical (Eq.(1)). Intermediate chain reaction product, $\mathrm{H}_{2} \mathrm{O}_{2}$, which is a relatively good oxidant, undergoes two-electron reduction (Eq.(4)) to give $\mathrm{OH}^{-}$(in basic solution) and $\mathrm{H}_{2} \mathrm{O}$ (in acidic media) $[8,9]$.

$$
\begin{aligned}
& \mathrm{O}_{2} \stackrel{+e_{-}}{\longrightarrow \mathrm{O}_{2}^{--}} \\
& 2 \mathrm{O}_{2}^{--}+2 \mathrm{H}^{+} \longrightarrow \mathrm{H}_{2} \mathrm{O}_{2}+\mathrm{O}_{2}\left(\mathrm{a}^{1} \Delta_{\mathrm{g}}\right) \\
& 2 \mathrm{O}_{2}^{--}+2 \mathrm{H}_{2} \mathrm{O} \longrightarrow \mathrm{H}_{2} \mathrm{O}_{2}+2 \mathrm{OH}^{-} \\
& \mathrm{H}_{2} \mathrm{O}_{2}+2 \mathrm{e}^{-} \longrightarrow 2 \mathrm{OH}^{-} \\
& \mathrm{H}_{2} \mathrm{O}_{2}+2 \mathrm{e}^{-+}+2 \mathrm{H}^{+} \longrightarrow 2 \mathrm{H}_{2} \mathrm{O}
\end{aligned}
$$

\section{Oxidation of Tannins}

It is known that tannins dissolved in water solution and exposed to air, within room temperature, could follow autooxidation reactions rapidly. Therefore, it is indicated to carefully manage tannins extraction, separation and their storage conditions $[10,11]$.

Tannin polyphenols are a large class of compounds that could be divided into two general sub-classes: condensed tannins and hydrolyzable tannins. Grape seed tannins contain more predominantly condensed tannins, which contain polymers formed by condensation via $\mathrm{C} 4 \rightarrow \mathrm{C} 8$ carbon-carbon bond between catechin (epicatechin) monomer units, as showed in Figure $1[1,12]$. 


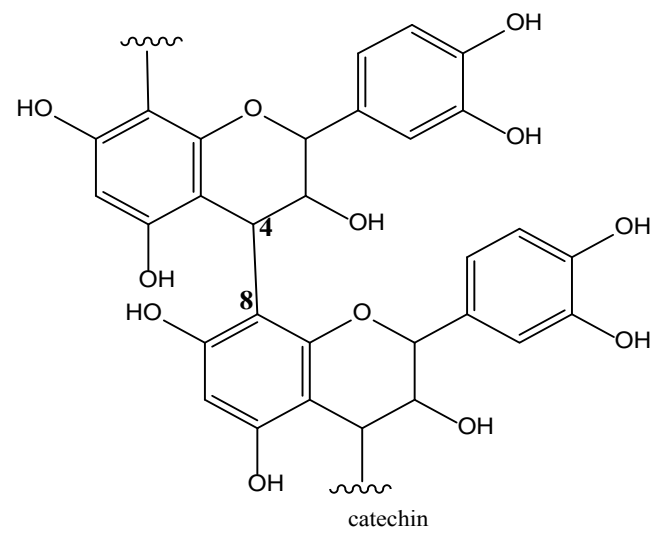

Figure 1. General enotannin structure [1].

Although oxidative cleavage of tannins involves a complex mechanism, several oxidation attempts have been investigated for monomer units in model solutions, like oxidation of quercetin, catechin and others flavanoids $[13,14]$. In Figure 2, it is represented the mechanism of $\mathrm{H}$-abstraction and electron detachment from a quercetin molecule, in alkaline conditions [14].<smiles>O=c1c(O)c(-c2ccc(O)c(O)c2)oc2cc(O)cc(O)c12</smiles>

quercetin

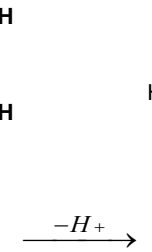

(a)<smiles>O=c1c(O)c(-c2ccc(O)c(O)c2)oc2cc(O)cc(O)c12</smiles>

semiquinone anion form

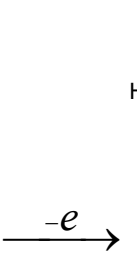

(b)<smiles>O=c1c(O)c(-c2ccc(O)c(O)c2)oc2cc(O)cc(O)c12</smiles>

semiquinone radical form

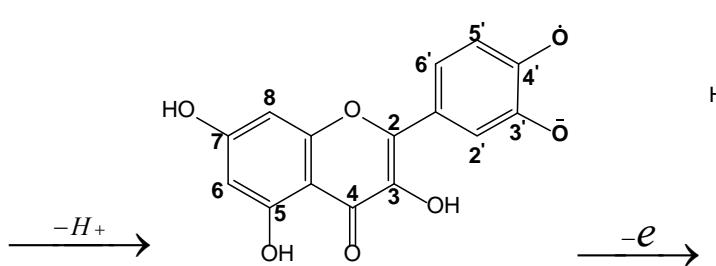

(c) semiquinone anion radical form<smiles>O=C1C=CC(c2oc3cc(O)cc(O)c3c(=O)c2O)=CC1=O</smiles>

quinone product $(P)$

Figure 2. Schematic mechanism representation for quercetin autooxidation in alkaline conditions.

In order to elucidate the corresponding mechanism involved in these oxidation reactions, it is necessary the presence of several key-determinants in one's molecule structure, to be taken into account. The mechanism for the first $\mathrm{H}$-abstraction from B-ring, which is a catechol moiety, is mainly due to the pKa values for C4'-OH and C3'-OH present in the B-ring, which are lower than other pKa of carbon-hydroxyl sites from resorcinol (A-ring) in positions $\mathrm{C} 5-\mathrm{OH}, \mathrm{C} 7-\mathrm{OH}$ or from the heterocycle (C-ring) in position $\mathrm{C} 3-\mathrm{OH}$. This makes B-ring to be more affordable for oxidation attack by physical quenching mechanism $[14,15]$.

In a work by Bors et al., it is stipulated that three key-functional groups in the chemical structure of a polyphenol are the main cause of $\mathrm{H}$-abstraction and electron donor afterwards, influenced by resonance structure's stabilization of the molecule: (i) the 3',4'-dihydroxy in the catechol B-ring configuration, which after the donation of a hydrogen atom gives the most stable semiquinone radicals; (ii) the double effect, of 2,3-double bond with the C4-carbonyl group in the C-ring, favours relocation of an electron from the B-ring phenoxy radical structure to resorcinol A-ring, and (iii) the combination of the 2,3-double(C2-C3) bond in C-ring and the hydroxyl group at C3 position [16,17].

The most close molecule structure for aforementioned main characteristics, which is related to the prooxidant nature, is considered quercetin (Figure 2) [17].

Quercetin is a unique chemical molecule with remarkable antioxidant activities, which is being considered as one of the most potent antiradical among other flavanoids. Due to the presence of dihydroxyl groups on B-ring and the combination of the double bond in C-ring, quercetin has been used in different experiments for the inhibiting of free oxygen, peroxynitrite, DPPH and ABTS radicals $[18,19]$. Thus, amplified antioxidant properties are characteristic for quercetin, its ability to exert prooxidant activities has been remarked for low concentration in solutions up to $2 \mu \mathrm{mol} / \mathrm{L}$ [20]. For this reason the toxicity of quercetin, upon DNA damage by promoting of superoxide anion radicals, when used in vivo should be analyzed very carefully [21]. 
Nevertheless, in order to describe the complex oxidation mechanism of tannins, it is necessary to identify products obtained after oxidation by advanced separation on columns with specific stationary phase, due to mixed nature of polarity of the compounds, highly instrumentation detection as mass spectrometry (ESI-MS, APCI-MS), NMR, MALDI and others.

Nowadays, modification and utilization of ecologically neglected tannins extracted from wine industry waste by-products represent a high potential for obtaining of new polyfunctional materials with amplified therapeutic efficiencies. Moreover, Lupascu T. and co-workers have identified remarkable antibacterial and antifungal properties exerted by the new product (Enoxil), obtained after oxidation of enotannins. After chromatographic separations and identification of compounds by mass spectrometry detector, it was revealed that oxidized tannins mixture contain lower molecular weight compounds, such as catechin monomers, quercetin, carboxylic and peroxy components [2,22].

\section{Chemiluminescence detection- a promising tool}

Chemiluminescence (CL) is considered a light's production system, induced by chemical reactions, that involves direct transformation of a chemical into electronic energy. This type of reaction belongs to the class of luminescence interactions based on the relaxation energy obtained after transition from excited state of the molecules to their ground state. This lead to a structural rearrangement at the molecule electronic levels, that in result show different physical and chemical properties compared to the ground state of the molecule. An effective CL reaction requires important components, described as follows: (i) chemiluminescent substrate molecule by emitting light after excitation, or transferring the energy to another molecule; (ii) an electron acceptor such as oxygen, when involved in an oxidation reaction; (iii) catalyst, which may be an enzyme or a metal ion [23]. General reactions that are involved in a chemiluminescence assay are represented by the following reactions (Eq.(6-7)):

$\mathrm{T} \bullet \rightarrow \mathrm{T}+\mathrm{h} v$

$\mathrm{T} \bullet+\mathrm{A} \rightarrow \mathrm{T}+\mathrm{A} \bullet(\mathrm{CL}$ signal produced after transferring the energy to another molecule)

For the analysis and identification of reactive oxygen species, photoluminescence technique has been successful utilized. Baier J. and co-workers have measured luminescence of singlet oxygen at around $1.270 \mathrm{~nm}$, but the signal obtained is ultra weak and very short in time (microseconds to one second) that needs highly advanced instrumentation [7]. To the contrary, by using exogenous photo-sensitizer, the luminescence could be enhanced and is explained by involvement of red-ox chemical reaction, which leads to a chemiluminescence signal response [6,10]. The appearance of chemiluminescence emission during chemical reactions is known for a long time and is closely related to the formation of free radical intermediates. Chemiluminescence was observed during the oxidation of polycyclic aromatic hydrocarbons, especially in the oxidation reaction by hydrogen peroxide upon a range of compounds such as amino acids, proteins, liver homogenates, riboflavin and polyphenols. In most of the chemiluminescence assays, it have been used oxidation reactions between a sensitizer (luminol, lucigen) and an oxidant specie $\left(\mathrm{H}_{2} \mathrm{O}_{2}\right)$ present in alkaline solution, intended for the determination of antioxidant activities of natural flavanoids $[23,24]$.

Chemiluminescence detection has been used for the identification and calibration of tannic acid [25], quercetin [26] and catechin [27]. In all these experiments, phenolic compounds with prooxidant activities are involved.

An enhancement of luminescence was observed after addition of quercetin in the CL, generation system Luminol/Carbonate buffer ( $\mathrm{pH}=9.9)$, that was correlated to the $\mathrm{ROS}$ involved in the autoxidation of quercetin in alkaline aqueous solution. This enhancement was due to the existence of semiquinone radical anion form of quercetin in solution (Figure 2), that led to the superoxide radical anion by electron donation to oxygen molecule (Eq.(1)). Similar process of $\mathrm{O}_{2}{ }^{-}$formation (see Eq.(11)) is involved in oxidation reaction of luminol (LumH). In result, more potent $\mathrm{O}_{2}{ }^{-}$molecules, will interact with diazosemiquinine radical anion (Lum*) and more content of luminol endoperoxide $\left(\mathrm{LumO}_{2}{ }^{2-}\right)$ will be produced (see Eq.(12)). The following reactions (see Eq.(8-14)) describe the oxidation processes of initial luminol (LumH) to final product, $\left(\mathrm{D}^{2-}\right)$, obtained after heterocycle opening and elimination of $\mathrm{N}_{2}$. Chemiluminescent signal $(h v)$ occurs after transition of $\left(\mathrm{D}^{2-*}\right)$, in the lowest excited single state, to to the less vibrationally excited state $\left(\mathrm{D}^{2-}\right)$ [28].

$$
\begin{aligned}
& \mathrm{LumH} \stackrel{\mathrm{OH}-}{\longrightarrow} \mathrm{Lum}^{-} \\
& \mathrm{Lum}^{-} \stackrel{-e^{-}}{\longrightarrow} \mathrm{Lum}^{\cdot} \\
& \mathrm{Lum}^{\cdot-} \stackrel{-\mathrm{H}}{\longrightarrow} \mathrm{Lum}^{--} \\
& \mathrm{Lum}^{\cdot-} \stackrel{\mathrm{O}_{2}}{\longrightarrow} \mathrm{Lum}^{+} \mathrm{O}_{2}^{--} \\
& \mathrm{Lum}^{\cdot-}+\mathrm{O}_{2}^{--}\left(\text {or }_{2}\left(\mathrm{a}^{1} \Delta_{\mathrm{g}}\right)\right) \longrightarrow \mathrm{LumO}_{2}^{2-} \\
& \mathrm{LumO}_{2}^{2-} \longrightarrow \mathrm{D}^{2-*}(\text { the lowest excited single state })+\mathrm{N}_{2} \\
& \mathrm{D}^{2-*} \longrightarrow \mathrm{D}^{2-}(\text { less vibrationally excited state })+h v, \lambda=428 \mathrm{~nm}
\end{aligned}
$$




\section{Fenton reaction}

Fenton chemistry is widely used in scientific researches as source of free $\mathrm{OH}^{\cdot}$ radicals. A special interest is accorded for Fenton type reactions and their importance in environmental science, as a catalytic oxidation mechanism for water pollutants removal [29,30]. In Eq.(15) is described the formation of $\mathrm{OH}^{*}$ radicals, which could be involved in further production of free radicals (Eq.(16)) [6].

$$
\begin{aligned}
& \mathrm{Fe}^{2+}+\mathrm{H}_{2} \mathrm{O}_{2} \longrightarrow \mathrm{Fe}^{3+}+\mathrm{OH}^{\cdot}+\mathrm{OH}^{-} \\
& \mathrm{H}_{2} \mathrm{O}_{2}+\mathrm{HO}^{-} \rightarrow \mathrm{O}_{2}^{--}-+\mathrm{H}_{3} \mathrm{O}^{+} \text {(in alkaline solutions) }
\end{aligned}
$$

As have been mentioned, chemiluminescence analysis is a fast and reliable method for the determination of prooxidant/antioxidant potential of natural polyphenols. The goal of this work was to interpret the general aspects related to the autooxidation mechanism of low molecular polyphenolic compounds, obtained after depolymerization of enotannins, by using an enhanced chemiluminescence assay. In addition, it has been discussed the pathway of luminescent light's production after physico-chemical interaction of ROS with flavanoids, in mild alkaline solutions, in the presence of $\mathrm{Fe}^{2+}$ ions as catalyst.

\section{Experimental \\ Apparatus}

In this work Luminometer, Promega Glomax 20/20, USA, with photomultiplier tube (PMT) detector and spectral range between 350-650 nm, have been used. Luminescence sensitivity expressed as relative luminescence units $\left(10^{2}-10^{9}, \mathrm{RLU}\right.$, with an accuracy \pm 50$)$. Relative luminescence units (a.u.) have been recorded as total sum of photon counts $/ 10$ seconds over the range $350-650 \mathrm{~nm}$.

\section{Reagents}

For these experiments have been used: Tris-EDTA buffer, pH 8.0 (BioUltra, 99\% purity); oxidized tannins (Tox) were obtained by oxidation reactions of the enotannins of local origin, several concentrations of Tox in distilled water have been prepared, in the [Tox] range between $0.005-0.8 \%\left(\mathrm{~g} / 100 \mathrm{~mL} \mathrm{H} \mathrm{H}_{2} \mathrm{O}\right)$; Moh'r salt solution $\left(\mathrm{Fe}^{2+}\right.$ ion source, $\left[\mathrm{Fe}^{2+}\right]=0.001 \mathrm{~mol} / \mathrm{L}$ ) and distilled water. The motivation of the use Moh'r salt in these experiments, relay on the consideration that $\mathrm{Fe}$ (II) present in this salt is more resistant to oxidation than in ferrous sulphate $\left(\mathrm{FeSO}_{4}\right)$, due to the presence of acidifying ammonium ions.

\section{Chemiluminescence assay}

For the reference sample, in a microcentrifuge tube of $1.5 \mathrm{~mL}, 200 \mu \mathrm{L}$ of Tox solution have been accurately transferred followed by the addition of $800 \mu \mathrm{L}$ of Tris-EDTA buffer. The luminescence data have been collected in the Excel program, exactly after 10 seconds from initial mixing. In case of chemiluminescence signal enhancement, triggered by $\mathrm{Fe}^{2+}$ ions, $200 \mu \mathrm{L}$ Tox solution have been transferred to $1.5 \mathrm{~mL}$ centrifuge tube, followed by simultaneously addition of $750 \mu \mathrm{L}$ of Tris-EDTA buffer and $50 \mu \mathrm{L}$ of Fe(II) solution (Mohr salt) with the data collection after the same 10 seconds.

\section{Results and discussion}

Although Tox represent a complex mixture of compounds obtained after tannin oxidation, for simplicity it has been treated as a whole chemical entity molecule in this work.

Occurrence of superoxide radical anion (Eq.(1)) is accomplished by the transition of an electron, released from semiquinone anion radical of Tox (Tox*), to molecular oxygen, similar to the mechanism presented in Figure 2, (Eq. (17)). Furthermore, $\mathrm{O}_{2}^{--}$by proton's addition, led to the formation of hydrogen peroxide and oxygen singlet (Eq.(18)) [30,31]. As a consequence of polyphenol oxidation in mild to strong alkaline ( $\mathrm{pH}$ 7.5-11.5) solutions, a weak chemiluminescent signal was exhibited. This yellow-green light, arises from a charge-transfer intramolecular character, which favours the ultrafast intermediary formation of the lowest excited state specie (ToxQ ${ }^{2-*}$, Eq.(21)). Occurrence of intermediary peroxide dianion form ( $\mathrm{ToxO}_{2}^{2-}$, Eq.(20)) is due to the chemical type addition of $\mathrm{O}_{2}\left(\mathrm{a}^{1} \Delta_{\mathrm{g}}\right.$ ) by flavonol (Tox) mainly responsible for oxygen attack on C-ring, with C4-oxy-group and C2-C3 double bond [32-35].

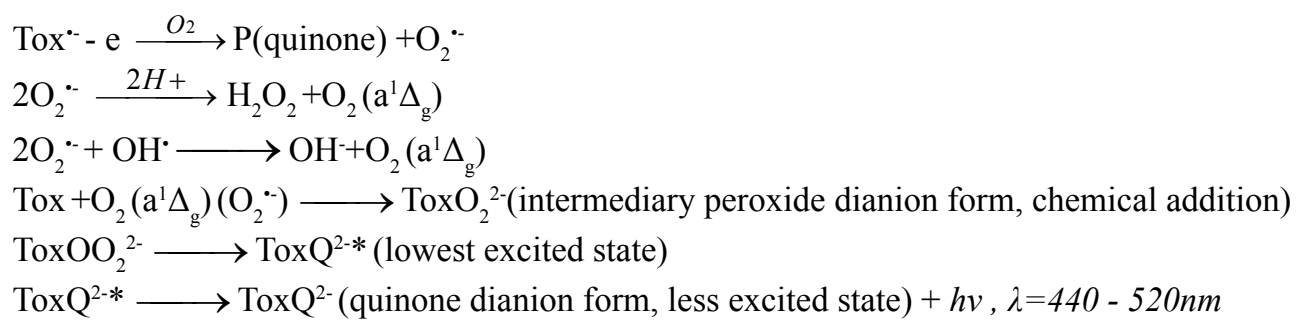


Lifetime of singlet oxygen, in protic media solutions, is from 1-200 $\mu$ s depending on the solvent media used (ethanol, acetonitrile, acetone, DMSO). To the contrary, superoxide radical is extremely long-lived in alkaline media [36]. Therefore more content of $\mathrm{O}_{2}{ }^{-}$present in alkaline solution catalyse the formation of the singlet oxygen, which by radiative deactivation of the excited state $\mathrm{O}_{2}\left(\mathrm{a}^{1} \Delta_{\mathrm{g}}\right)$ would give $\mathrm{O}_{2}\left({ }^{3} \sum_{\mathrm{g}}^{-}\right)$- in triplet ground state with a maximum at $\lambda=635 \mathrm{~nm}$ as shown in the following reaction (Eq.(23)) [37]:

$$
2 \mathrm{O}_{2}\left(\mathrm{a}^{1} \Delta_{\mathrm{g}}\right)\left(\mathrm{a}^{1} \sum_{\mathrm{g}}^{-}\right) \longrightarrow 2 \mathrm{O}_{2}\left({ }^{3} \sum_{\mathrm{g}}^{-}\right)+h v, \lambda=635 \mathrm{~nm}
$$

Although this is the direct way of the photon's emission resulted after transition of excited state of oxygen singlet to its triplet ground state, this light is quite difficult to quantify. Nevertheless other indirect ways of light's emission could be also involved. In a work by Tournaire C. et al., it has been suggested that weak light has been observed after physical interaction of flavanol molecule with oxygen singlet (Eq.(24)). This was characterized by the energy transferred to a flavanol (Flv) molecule (Eq.(7)), resulted in the radiative deactivation of $\mathrm{O}_{2}\left(\mathrm{a}^{1} \Delta_{\mathrm{g}}\right)$ (Eq.(23)). Afterwards, it follows the same processes as explained in reaction given by Eq.(6) with photon emission in the range of 420-520nm [38].

$$
2 \mathrm{O}_{2}\left(\mathrm{a}^{1} \Delta_{\mathrm{g}}\right)\left(\mathrm{a}^{1} \sum_{\mathrm{g}}^{-}\right)+\mathrm{Flv} \longrightarrow 2 \mathrm{O}_{2}\left({ }^{3} \sum_{\mathrm{g}}^{-}\right)+\mathrm{Flv}^{*}
$$

The ability of polyphenols in reduction of $\mathrm{Fe}^{3+}$ ions (Eq.(15)) in aqueous solution, by a physical interaction between phenolate anion (Tox) and $\mathrm{Fe}^{3+}$ ions, would trigger so called "Fenton-like reactions", due to the indirect mechanism of reactions, which led to the formation of $\mathrm{Fe}^{2+}$ ions and resume the $\mathrm{OH}^{\cdot}$ production (Eq.(15)) [6,39].

$$
\mathrm{Tox}^{-}+\mathrm{Fe}^{3+} \longrightarrow \mathrm{Fe}^{2+}+\mathrm{Tox}^{*}
$$

Combining the reactions described by the Eqs.(17-25), we would get a general view for the initiation, propagation and catalytic influence on the autooxidation reactions of polyphenols (Figure 3) [40].<smiles>Oc1cc(O)c2c(c1)OC(c1ccc(O)c(O)c1)C(O)C2</smiles>

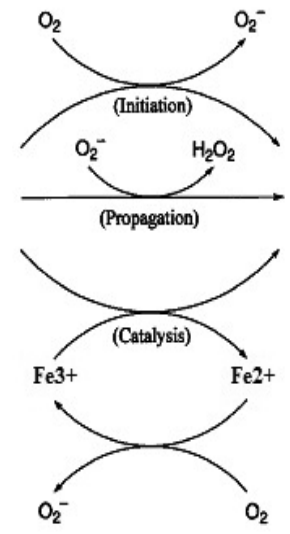<smiles>Oc1cc(O)c2c(c1)OC(c1ccc(O)c(Cl)c1)C(O)C2</smiles><smiles>CC(C)C(=O)C(C)C</smiles>

Figure 3. Mechanism of catechin's autooxidation in the presence of catalyst (adapted and modified according to [40]).

As have been mentioned, a weak luminescent light is formed by initiation of autooxidation reactions of polyphenols in mild to strong alkaline solutions advocated by the reactions described in Eq.(17-22). The interval characteristic for a weak luminescence is between $1 \cdot 10^{2}-1 \cdot 10^{5}$ (RLU, a.u.), while a high level intensity luminescence corresponds to the range between $1 \cdot 10^{5}-1 \cdot 10^{9}$ (RLU, a.u.)

After mixing $200 \mu \mathrm{L}$ of polyphenols with $800 \mu \mathrm{L}$ of Tris-EDTA, luminescent light have been measured exactly after 10 seconds, counting from the initial mixing. In Figure 4, it can be seen that weak light ( $\max$ RLU=246 a.u.), is formed, which corresponds to the autooxidation reactions of Tox in mild alkaline solutions (Tris-EDTA, $\mathrm{pH} 8.0$ ), increasing insignificantly by variation in Tox concentration $(0.005-0.5, \%)$. 


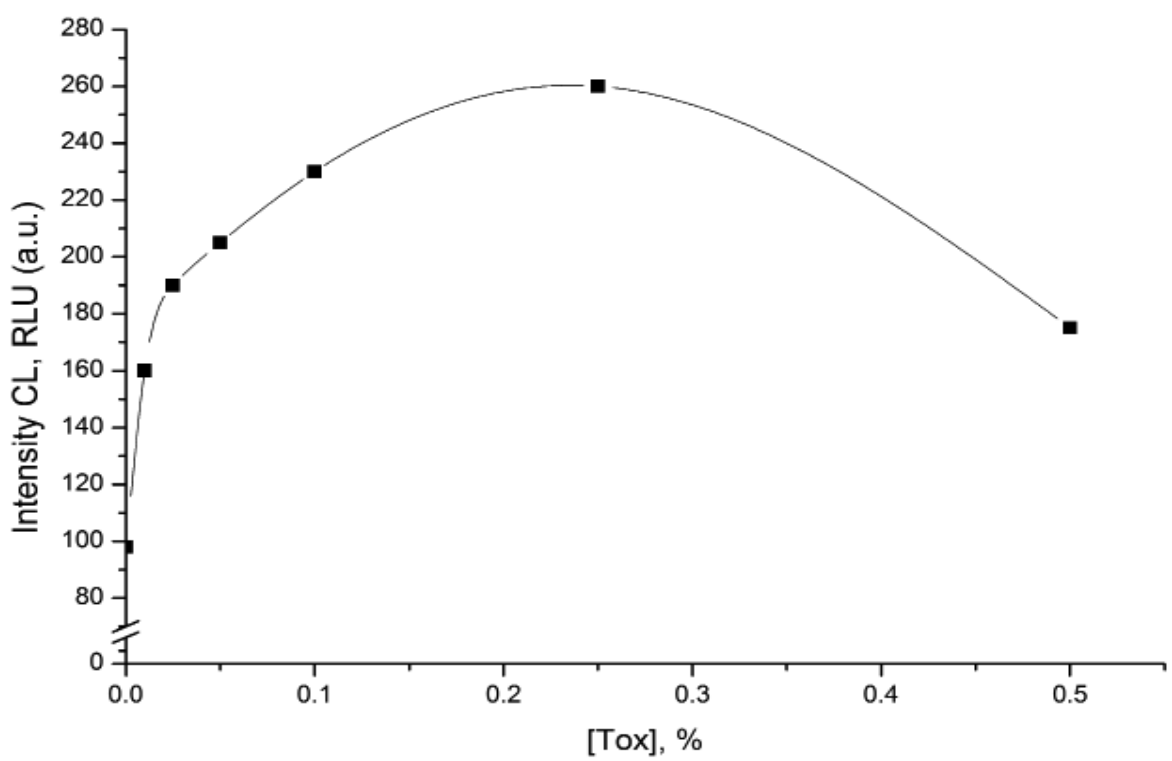

Figure 4. Chemiluminescent signal obtained in a CL generation system, Tox-Tris-EDTA pH 8.0, by increasing the Tox aqueous concentrations (\%).

These results corroborates with the work by Slawinska D. and co-workers, where only a weak light was emitted, that has been interpreted as the sum of photon's distribution pattern over the range of 440-520 nm.

To the contrary by adding to the $\mathrm{CL}$ assay, $\mathrm{Fe}^{2+}$ ions, the luminescence light measured was almost 7 times higher as compared with a CL reaction without ferrous ions. In Table 1 it is presented the data obtained after CL light's measurement for Tox aqueous concentrations $(0.005-0.1, \%)$.

Table 1

Luminescence detection (RLU, a.u.) in a CL generation system, Tox/Tris-EDTA/Fe ${ }^{2+}$ for a range of Tox concentrations $(0.005-0.1, \%)$ obtained after 10 seconds from initial mixing.

\begin{tabular}{ccc}
\hline Concentration of Tox, \% & $R L U($ a.u. $)$ with $\mathrm{Fe}^{2+}$ & $R L U$ (a.u.) without Fe ${ }^{2+}$ \\
\hline 0.005 & $230 \pm 10$ & $124 \pm 12$ \\
0.01 & $370 \pm 35$ & $157 \pm 23$ \\
0.02 & $490 \pm 41$ & $190 \pm 27$ \\
0.04 & $750 \pm 23$ & - \\
0.06 & $990 \pm 25$ & $205 \pm 16$ \\
0.08 & $1235 \pm 38$ & - \\
0.1 & $1450 \pm 46$ & $230 \pm 24$ \\
\hline
\end{tabular}

Note: all measurements have been done in triplicate

Interestingly that CL intensity (RLU, a.u.) is increasing linearly over the range of CL (200-2000, a.u.), with a linear regression $\left(\mathrm{R}^{2}=0.9994\right)$, which could be considered a confident result when a calibration curve should be obtained for the modified tannin (see Figure 5). However this increase is linearly only in the [Tox] $\geqq 0.1 \%$ (Figures 5 and 6). Further experiments are required for a deep analysis of inter-dependency conditions such as optimal concentrations of ferrous ions, detection of hydrogen peroxide content, specification of ROS species involved $\left(\mathrm{OH}^{\circ}, \mathrm{O}_{2}{ }^{-}, \mathrm{O}_{2}\left(\mathrm{a}^{1} \Delta_{\mathrm{g}}\right)\right.$ in oxidation mechanism, instrument's limit of detection and the interference by other chemical species that could influence the result.

Although the change in the concentration of Tox aqueous solutions is directly proportional to the increase in the chemiluminescent signal (Figure 5), in the case [Tox] $\geqq 0.25 \%\left(\mathrm{~g} / 100 \mathrm{~mL} \mathrm{H}_{2} \mathrm{O}\right)$ a decrease of the luminescent light have been noticed (Figure 6). 


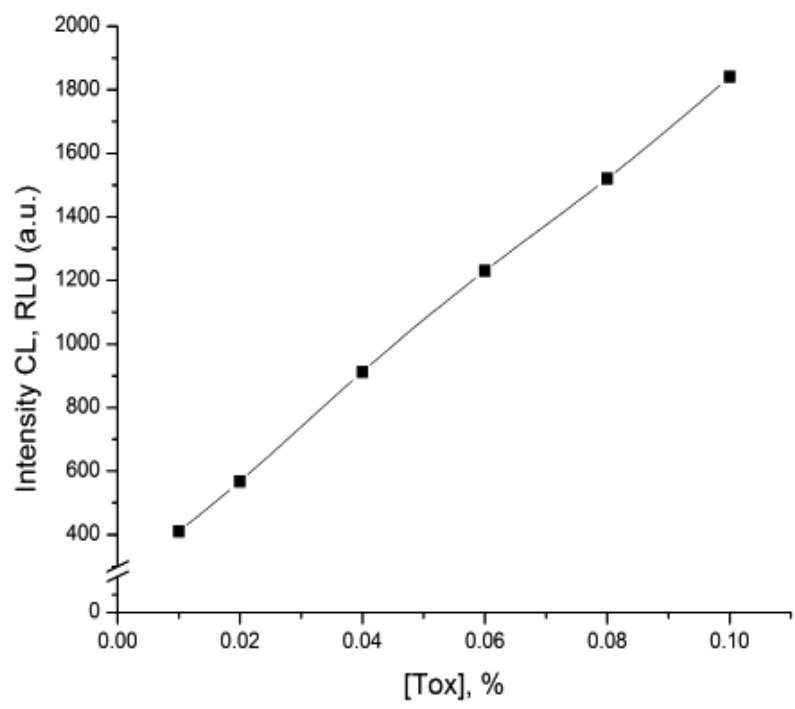

Figure 5. Decreasing luminescence versus increasing amount of [Tox] in a CL generation system, with $\mathrm{Fe}^{2+}$ ions.

This phenomena could explained by Tox participation in ROS production (Eqs.(17-25)), in the first place, for $[$ Tox $]<0.25 \%$, which is associated to the prooxidant activities exerted by polyphenols. At such lower concentration of Tox, it is believed that the rate of formation $\left(\mathrm{R}_{\mathrm{f}}\right)[\mathrm{ROS}]>[$ Tox] with reduction properties available in the solution and will determine the formation of an oxidizing environment. Moreover, the reactions are mainly oriented to the initiation and propagation of chain reactions involving free radicals, which led to chemiluminescent light emission.

To the contrary, for [Tox] $\geqq 0.25 \%$, antioxidant free radical scavenger reactions are more likely to occur. This could be explained by a predominant polyphenol proton-donation transfer to ROS free radicals, which will result in their inhibition.

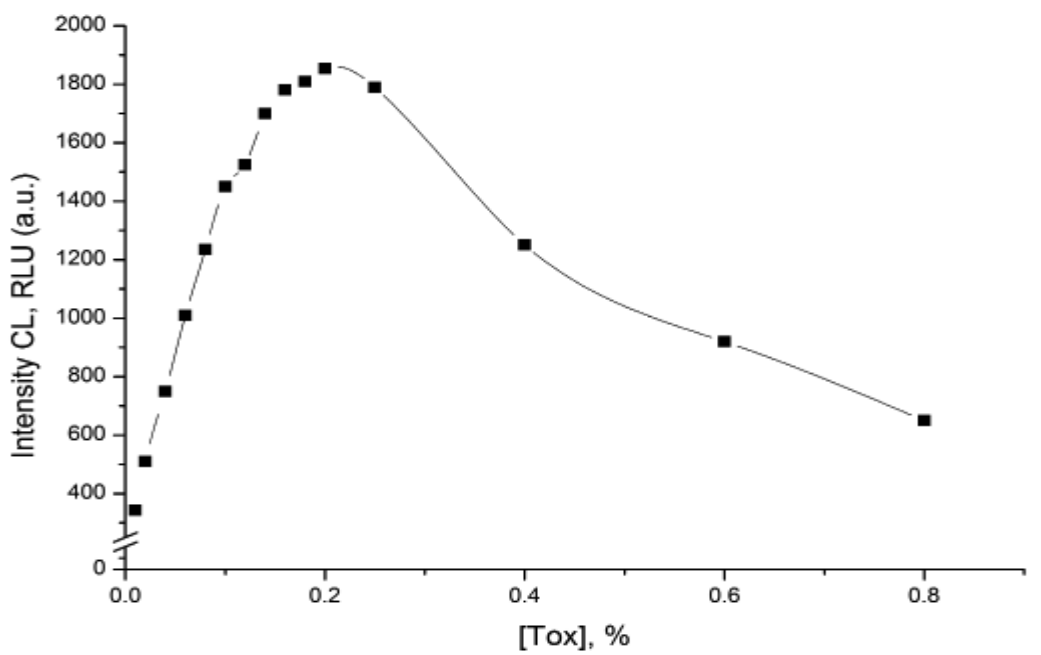

Figure 6. Decreasing luminescence versus increasing amount of [Tox] in a CL generation system, with $\mathrm{Fe}^{2+}$ ions.

According to this situation [Tox] $\geqq 0.25 \%$, the prevalence in solution of Tox molecules, with proton-donor properties, would inhibit ROS in the first place. This environment could be characterized as a system with predominant reducing properties. This affirmation corroborate with our previous work, where for values of [Enoxil] $\geqq 0.3 \%$ $\left(\mathrm{g} / 100 \mathrm{~mL} \mathrm{H}_{2} \mathrm{O}\right)$ there is an increase of antioxidant activities (by $45 \%$ ) compared to initial tannins, determined by $\mathrm{ABTS}^{\cdot+}$ and DPPH assay [41]. 


\section{Conclusions}

In this work, it is described a general overview of autooxidation's reaction mechanism of polyphenols obtained after enotannin modification and chemiluminescence signal occurrence afterwards. Polyphenols in alkaline solutions are subject to autooxidation reactions, that could generate in result ROS (hydrogen peroxide, superoxide radical anion and oxygen singlet) by $\mathrm{H}$-abstraction and proton-donor pathway. The catechol moiety on B-ring, in the flavanoid structure, is more susceptible for oxidation reactions by ROS through physical quenching, while chemical oxidation reactions are mainly involved on C-ring's, which has the oxy-group and carbon-carbon double bond. In this experiment, a light generation system has been developed, using oxidized tannin/Tris-EDTA/ $\mathrm{Fe}^{2+}$ ions in the range of detection $\lambda=360-650$, and a detailed explanation of this light occurrence have been presented. It has been observed that addition of ferrous ions into the system, led to an enhancement of chemiluminescence light by Fenton-like reactions. The CL intensity was direct proportional to increasing Tox concentrations $(0.005-0.1, \%)$. It have been established, that for [Tox] $<0.25 \%$, ROS formation is promoted, but for [Tox] $\geqq 0.25 \%$, free radical scavenger ability is enhanced and ROS formation was inhibited.

Due to a complex mixture of compounds obtained after tannin modification, further experiments are required for identification of components responsible for generation of active free radicals or for the antioxidant properties, respectively.

\section{Acknowledgements}

Author is thankful to Dr. Nina Timbaliuc for experimental assistance and supervisor Prof., Dr. Habilitate Tudor Lupascu for guidance and suggestions.

\section{References}

1. Kulciţki, V.; Vlad, P.; Duca, Gh. Investigation of grape seed proantocyanidins. Chemistry Journal of Moldova, 2007, 2(1), pp. 36-50.

2. $\quad$ Lupascu, T.; Duca, G.; Giurginca, M.; Vlad, P.; Lupascu, L.; Gromovoi, T.; Meghea, A. Natural Compounds with Antioxidant Properties. Key Engineering Materials, 2009, 415, pp. 25-28.

3. Muselík, J.; García-Alonso, M.; Martín-López, M.P.; Žemlička, M.; Rivas-Gonzalo, J.C. Measurement of antioxidant activity of wine catechins, procyanidins, anthocyanins and pyranoanthocyanins. International Journal of Molecular Sciences, 2007, 8(8), pp. 797-809.

4. Sengupta, P.K.; Kasha, M. Excited state proton-transfer spectroscopy of 3-hytdroxyflavone and quercetin. Chemical Physics Letters, 1979, 68(2-3), pp. 382-385.

5. Li, S.; Qian, L.; Zhu, Y.; Liu, M.; Gao, Y.; Ni, Y. Enhanced chemiluminescence of cerium(IV)-Tween 85 system and the analytical application. Luminescence, 2013, 28(6), pp. 948-953.

6. Ivanova, I.P. Mechanism of chemiluminescence in Fenton reaction. Journal of Biophysical Chemistry, 2012, 3(1), pp. $88-100$.

7. Baier, J.; Maisch, T.; Maier, M.; Landthaler, M.; Baumler, W. Direct detection of singlet oxygen generated by UVA irradiation in human cells and skin. Journal of Investigative Dermatology, 2007, 127(6), pp. 1498-1506.

8. Duca, Gh. Homogeneous catalysis with metal complexes: fundamentals and applications. Springer Series in Chemical Physics: Germany, 2012, 480 p.

9. Foote, C.S. Active oxygen in chemistry. Springer series Structure Energetics and Reactivity in Chemistry: Netherlands, 1995, 342 p.

10. Tuominen, A.; Sundman, T. Stability and oxidation products of hydrolysable tannins in basic conditions detected by HPLC/DAD-ESI/QTOF/MS. Phytochemical Analysis, 2013, 24(5), pp. 424-435.

11. Poncet-Legrand, C.; Cabane, B.; Bautista-Ortín, A.-B.; Carrillo, S.; Fulcrand, H.; Pérez, J.; Vernhet, A. Tannin oxidation: intra- versus intermolecular reactions. Biomacromolecules, 2010, 11(9), pp. 2376-2386.

12. Hagerman, A.E.; Riedl, K.M.; Jones, G.A.; Sovik, K.N.; Ritchard, N.T.; Hartzfeld, P.W.; Riechel, T.L. High molecular weight plant polyphenolics (tannins) as biological antioxidants. Journal of Agricultural and Food Chemistry, 1998, 46(5), pp. 1887-1892.

13. Xu, G.; In, M.Y.; Yuan, Y.; Lee, J.; Kim, S. In situ spectroelectrochemical study of quercetin oxidation and complexation with metal ions in acidic solutions. Bulletin of the Korean Chemical Society, 2007, 28(5), pp. 889892.

14. Janeiro, P.; Oliveira Brett, A. M. Catechin electrochemical oxidation mechanisms. Analytica Chimica Acta, 2004, 518(1-2), pp. 109-115.

15. Cren-Olivé, C.; Wieruszeski, J. M.; Maes, E.; Rolando, C. Catechin and epicatechin deprotonation followed by ${ }^{13} \mathrm{C}$ NMR. Tetrahedron Letters, 2002, 43(25), pp. 4545-4549.

16. Bors, W.; Michel, C.; Saran, M. Flavonoid antioxidants: rate constants for reactions with oxygen radicals. Methods in Enzymology, 1994, 234, pp. 420-429.

17. Abou Samra, M.; Chedea, V.S.; Economou, A.; Calokerinos, A.; Kefalas, P. Antioxidant/prooxidant properties of 
model phenolic compounds: Part I. Studies on equimolar mixtures by chemiluminescence and cyclic voltammetry. Food Chemistry, 2011, 125(2), pp. 622-629.

18. Iacopini, P.; Baldi, M.; Storchi, P.; Sebastiani, L. Catechin, epicatechin, quercetin, rutin and resveratrol in red grape: Content, in vitro antioxidant activity and interactions. Journal of Food Composition and Analysis, 2008, 21(8), pp. 589-598.

19. Prior, R.; Wu, X.; Schaich, K. Standardized methods for the determination of antioxidant capacity and phenolics in foods and dietary supplements. Journal of Agricultural and Food Chemistry, 2005, 53(10), pp. 4290-4302.

20. Kolewski, P.; Siger, A.; Nogala-kałucka, M.; Polewski, K. Evaluation of antioxidant activity of alpha-tocopherol and quercetin during oxidation of phosphatidylcholine using chemiluminescent detection. Polish Journal of Food and Nutrition Sciences, 2009, 59(2), pp. 123-127.

21. Babich, H.; Schuck, A.G.; Weisburg, J.H.; Zuckerbraun, H.L. Research strategies in the study of the pro-oxidant nature of polyphenol nutraceuticals. Journal of Toxicology, 2011, 2011, pp. 1-12.

22. Lupascu, T.; Kulciţki, V.; Vlad, P.; Duca, Gh.; Nastas, R. Studies on the water solubilization processes of oenotannins and their physico-chemical properties. Chemistry Journal of Moldova, 2006, 1(1), pp. 74-80.

23. Roda, A.; Guardigli, M. Analytical chemiluminescence and bioluminescence: Latest achievements and new horizons. Analytical and Bioanalytical Chemistry, 2012, 402(1), pp. 69-76.

24. Roda, A.; Pasini, P.; Guardigli, M.; Baraldini, M.; Musiani, M.; Mirasoli, M. Bio- and chemiluminescence in bioanalysis. Fresenius Journal of Analytical Chemistry, 2000, 366(6-7), pp. 752-759.

25. Xie, C.; Cui, H. Detection of tannic acid at trace level in industrial wastewaters using a highly sensitive chemiluminescence method. Water Research, 2003, 37(1), pp. 233-237.

26. Lei, R.; Xu, X.; Yu, F.; Li, N.; Liu, H.W.; Li, K. A method to determine quercetin by enhanced luminol electrogenerated chemiluminescence (ECL) and quercetin autoxidation. Talanta, 2008, 75(4), pp.1068-1074.

27. Lee, J.M.; Karim, M.M.; Lee, S.H. Determination of catechin in aqueous solution by chemiluminescence method. Journal of Fluorescence, 2005, 15(5), pp. 735-739.

28. Brunmark, A.; Cadenas, E. Electronically excited state generation during the reaction of p-benzoquinone with $\mathrm{H}_{2} \mathrm{O}_{2}$ : Relation to product formation: 2-OH- and 2,3-epoxy-p-Benzoquinone the effect of glutathione, Free Radical Biology and Medicine, 3(3), 1987, pp. 169-180.

29. Soon, A.N.; Hameed, B.H. Heterogeneous catalytic treatment of synthetic dyes in aqueous media using Fenton and photo-assisted Fenton process. Desalination, 2011, 269(1), pp. 1-16.

30. Gonta, M.; Duca, Gh.; Matveevici, V.; Mocanu L. The diminishing of the content of textile direct dyes and auxiliary compounds during their catalytic oxidation. Chemistry Journal of Moldova, 2014, 9(1), pp. 85-92.

31. Kruk, I.; Michalska, T.; Kładna, A. Luminescence in the oxidation of isoproterenol by the superoxide anion radical in dimethyl sulfoxide. Toxicological \& Environmental Chemistry, 1998, 67(3-4), pp. 293-304.

32. Slawinska, D. Chemiluminescence and the formation of singlet oxygen in the oxidation of certain polyphenols and quinones. Photochemistry and Photobiology, 1978, 28, pp. 453-458.

33. Sengupta, B.; Reilly, S.M.; Davis D.E.; Harris, K.; Wadkins, R.M.; Ward, D.; Gholar, A.; Sengupta, H. Excited State Proton Transfer of Natural Flavonoids and Their Chromophores in Duplex and Tetraplex DNAs. The Journal of Physical Chemistry B, 2015, 119 (6), pp. 2546-2556.

34. Morales, J.; Günther, G.; Zanocco, A.L.; Lemp, E. Singlet oxygen reactions with flavonoids. a theoretical experimental study. PLoS ONE, 2012, 7(7), pp. 1-8.

35. Mukherjee, T. Photo and radiation chemistry of quinones. Proceedings-Indian National Science Academy part A, 2000, 66(2), pp. 239-266.

36. Steeden, S.; Tosic, M.; Marjanovic, B.; Simicg, M.G. Flavonoids as Antioxidants. Journal of the American Chemical Society, 1994, 116(11), pp. 4846-4851.

37. Slawinska, D. Chemiluminescence in the peroxidation of tannic acid. Photochemistry and Photobiology, 1979, 30(1), pp. 71-80.

38. Tournaire, C.; Croux, S.; Maurette, M.T.; Beck, I., Hocquaux, M.; Braun, A.M.; Oliveros, E. Antioxidant activity of flavonoids: efficiency of singlet oxygen (1 delta g) quenching. Journal of Photochemistry and Photobiology B., Biology, 1993, 19(3), pp. 205-215.

39. Navas, D.; García Sánchez, F.; González García, J.A. Enhancement and inhibition of luminol chemiluminescence by phenolic acids. Journal of Bioluminescence and Chemiluminescence, 1995, 10(3), pp. 175-184.

40. Akagawa, M.; Shigemitsu, T.; Suyama, K. Production of hydrogen peroxide by polyphenols and polyphenolrich beverages under quasi-physiological conditions. Bioscience, Biotechnology, and Biochemistry, 2003, 67(12), pp. 2632-2640.

41. Lupascu T.; Gonta A. Studies on the antioxidant activity of the compound Enoxil and its related forms. Chemistry Journal of Moldova, 2011, 6(2), pp. 58-64. 